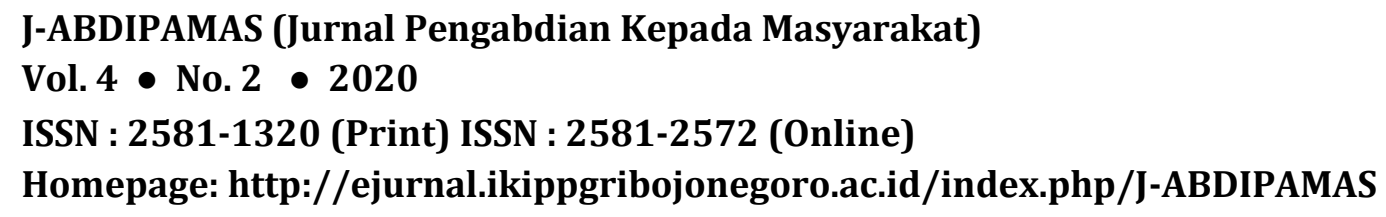

\title{
Olahan Pisang sebagai Penunjang Ekonomi Masyarakat di Sekitar Gunung Rajabasa Lampung
}

\author{
Rommy Qurniati ${ }^{1}$, Duryat 2 , Hendra Prasetia ${ }^{3}$, Ferli Hartati ${ }^{4}$ \\ ${ }^{1}$ Universitas Lampung. Email: rommy.qurniati@fp.unila.ac.id \\ 2Universitas Lampung. Email: duryat.1978@fp.unila.ac.id \\ 3Universitas Lampung. Email: hendra.prasetia@fp.unila.ac.id \\ ${ }^{4}$ Universitas Lampung. Email: ferlihartati@gmail.com
}

\begin{abstract}
Banana is one of the local fruit potentials that optimally have not been used. Many banana producers have complained about the low selling price. This is due to the lack of community knowledge on the food diversification products which made from banana as an alternative to improve the quality and price of bananas. The purpose of this community service activity was to increase knowledge and develop community creativity through the food diversification product of bananas by making the banana nuggets and flour. This activity was conducted on November 2019 in Banding and Sukaraja Village, Rajabasa District, South Lampung Regency. The applied method of this activity was a group meeting which the implementation includes three stages that was socialization, discussion, and evaluation. The results of the community service showed that community knowledge have been increased significantly after comparing the pretest and posttest results. The community was very enthusiastic about the activity because it was able to open their mindset about local fruit potentials that optimally have not been utilized, thus it was encouraged the community's desire to be creative on promoting local products that could increase the income.
\end{abstract}

Keywords: Banana, Local Potential, Nuggets, Flour, Community

\begin{abstract}
ABSTRAK
Pisang merupakan salah satu potensi buah lokal yang belum dimanfaatkan secara optimal. Produsen pisang masih banyak yang mengeluhkan harga jualnya yang rendah. Hal ini disebabkan karena kurangnya pengetahuan masyarakat tentang diversifikasi produk pangan berbahan baku pisang yang dapat menjadi alternatif dalam meningkatkan kualitas dan harga jual pisang. Tujuan dilakukannya kegiatan pengabdian kepada masyarakat ini adalah meningkatkan pengetahuan dan mengembangkan kreatifitas masyarakat melalui diversifikasi produk pangan berbahan baku pisang yaitu pembuatan nugget dan tepung pisang. Pengabdian ini dilaksanakan pada bulan November 2019 di Desa Banding dan Desa Sukaraja, Kecamatan Rajabasa, Kabupaten Lampung Selatan. Metode yang diterapkan dalam kegiatan ini adalah pertemuan kelompok yang pelaksanaannya meliputi tiga tahapan yaitu sosialisasi, diskusi, dan evaluasi. Hasil pengabdian yang dilakukan menunjukkan bahwa pengetahuan masyarakat meningkat secara signifikan setelah membandingkan hasil pretest dan posttest. Masyarakat sangat antusias dengan adanya kegiatan ini karena mampu membuka pola pikirnya mengenai potensi lokal yang belum dimanfaatkan secara optimal, sehingga mendorong keinginan masyarakat untuk berkreasi dalam mengedepankan produk lokal yang mampu meningkatkan pendapatan.
\end{abstract}

Kata Kunci: Pisang, Potensi Lokal, Nugget, Tepung, Masyarakat 


\section{PENDAHULUAN}

Sektor kehutanan menjadi salah satu sumber ketahanan pangan masyarakat Indonesia. Wujud kontribusi hutan terhadap kesediaan pangan dapat dilihat dari optimalisasi pemanfaatan potensinya. Berbagai potensi yang dihasilkan mampu menunjang ketahanan pangan masyarakat lokal, terutama pada hasil hutan bukan kayu (HHBK). Irundu and Fatmawaty (2019) mengungkapkan bahwa pengembangan HHBK tidak hanya mendukung ketahanan pangan saja, tetapi juga dapat dijadikan sebagai alternatif untuk meningkatkan pendapatan.

Pisang adalah salah satu produk HHBK yang saat ini menjadi komoditas unggulan. Kandungan gizi dan cita rasa yang tinggi mampu menggiring keinginan masyarakat untuk mengonsumsinya. Tidak hanya dikonsumsi secara langsung, pisang juga dapat diolah menjadi produk pangan yang berkualitas. Nilai jual pisang akan semakin meningkat apabila diproduksi dalam berbagai bentuk olahan, sehingga dapat menjadi peluang usaha yang mampu bersaing pada skala industri nasional (Fikriman et al., 2020).

Provinsi Lampung merupakan daerah penghasil pisang terbesar di Indonesia dengan jumlah produksi mencapai 14.385.590 ton/tahun (Statistik, 2015). Melimpahnya potensi pisang di daerah tersebut menyebabkan harga jual pisang semakin rendah. Hal yang sama juga diungkapkan oleh Tambajong et al. (2020) bahwa hasil panen pisang yang tinggi tidak dapat memberikan nilai tambah bagi produsen. Keadaan ini menimbulkan inisiatif masyarakat untuk menciptakan inovasi baru tentang produk olahan pisang. Pengembangan usaha yang mengutamakan produk olahan dengan memaksimalkan nilai ekonominya, akan memberikan pengaruh nyata terhadap pendapatan (Mangunsong et al., 2016).

Aneka produk pangan berbahan dasar pisang sebenarnya sudah banyak dikembangkan oleh masyarakat Lampung, tetapi belum diterapkan secara optimal. Hal ini disebabkan karena keterbatasan pengetahuan dan keterampilan masyarakat tentang diversifikasi bahan pangan berbasis lokal. Selain itu, banyaknya pelaku usaha yang memproduksi olahan pisang juga mengharuskan produsen untuk lebih kreatif dalam mengembangkan suatu produk. Oleh karena itu, perlu dilakukan langkah yang strategis untuk mendukung pengembangan industri rumah tangga dengan memanfaatkan potensi lokal.

Kegiatan penyuluhan dan pelatihan pembuatan produk olahan pisang berupa nugget dan tepung merupakan sebuah upaya dalam rangka meningkatkan kualitas dan nilai jual pisang. Tujuan dilakukannya program pemberdayaan masyarakat ini adalah meningkatkan pengetahuan dan mengembangkan kreatifitas serta keterampilan masyarakat secara partisipatif melalui diversifikasi produk pangan berbahan baku pisang. Hal ini diharapkan dapat membuka pandangan masyarakat tentang peluang usaha dan pemanfaatan potensi lokal yang memiliki nilai ekonomi tinggi. 


\section{METODE PELAKSANAAN}

Pengabdian ini dilaksanakan pada bulan November 2019 di Desa Banding dan Desa Sukaraja, Kecamatan Rajabasa, Kabupaten Lampung Selatan. Kedua desa mengembangkan tanaman pisang di Gunung Rajabasa yang merupakan area kelola dari Kesatuan Pengelolaan Hutan Lindung (KPHL) Rajabasa. Komoditi pisang dipilih karena tersedia melimpah dikedua desa tetapi belum dimanfaatkan secara optimal. Kegiatan ini ditujukan kepada ibu-ibu desa agar dapat meningkatkan produktivitas dan perekonomian keluarganya melalui diversifikasi produk pangan berbahan dasar pisang. Penyuluhan ini mendapatan dukungan penuh dari pihak KPHL Rajabasa dan didampingi langsung pada saat pelaksanaannya.

Perencaanaan, pelaksanaan, hingga evaluasi kegiatan ini melibatkan mahasiswa Jurusan Kehutanan Fakultas Pertanian Universitas Lampung yaitu Andi Rianto, Siti Fauzia Rochmah, Naradia Ayu Kartika, Laila Rahmawati, Adhi Aulia Fikri, Indah Rofifah, Melina Andriani, Reo Bagus Febrian, Hannan Rafiq Nasution, Ahmad Rizaldi, Ajeng Ayu Evi Rianti, dan Siti Neneng Nurjanah. Mahasiswa belajar membantu masyarakat agar mampu secara mandiri menolong dirinya sendiri untuk meningkatkan kesejahteraannya melalui peningkatan pengetahuan dan keterampilannya melalui penyampaian inovasi yang disampaikan. Dengan cara ini peningkatan pengetahuan dan keterampilan tidak hanya dicapai oleh masyarakat namun juga mahasiswa yang terlibat dalam penyuluhan ini.

Bahan yang digunakan adalah produk olahan pisang berupa nugget dan tepung, sedangkan alat yang digunakan yaitu media cetak berupa leaflet dan alat bantu kuesioner untuk pretest-posttest. Metode yang diterapkan dalam kegiatan ini adalah pertemuan kelompok yang pelaksanaannya meliputi tiga tahapan yaitu sosialisasi, diskusi, dan evaluasi.

\section{HASIL DAN PEMBAHASAN}

Kegiatan pengabdian masyarakat yang dilakukan di Desa Banding dan Desa Sukaraja memperkenalkan dua produk olahan pisang yang berbeda, yaitu nugget dan tepung. Penyuluhan nugget pisang dilakukan di Desa Banding, sedangkan penyuluhan tepung pisang dilakukan di Desa Sukaraja. Kedua desa tersebut memanfaatkan pisang dengan cara dijual langsung tanpa dilakukan pengolahan. Hal inilah yang menyebabkan nilai jual pisang menjadi rendah.

\section{Nugget Pisang}

Selama ini masyarakat hanya mengenal bahwa nugget diproduksi dalam bentuk olahan daging yang digiling. Berbeda halnya dengan kegiatan penyuluhan yang dilakukan di Desa Banding, bahan baku yang digunakan dalam proses pembuatan nugget adalah pisang. Hal ini merupakan sebuah terobosan baru dalam dunia kuliner yang belum banyak dikembangkan oleh masyarakat. Ide usaha kreatif mampu membuka peluang bagi masyarakat untuk menciptakan lapangan pekerjaan (Raharjo et al., 2016). 
Pelaksanaan kegiatan pembuatan nugget pisang diawali dengan melakukan pretest yang bertujuan untuk mengetahui tingkat pengetahuan peserta penyuluhan sebelum berlangsungnya kegiatan. Sebanyak 22 orang peserta hadir dalam kegiatan ini. Masing-masing peserta yang hadir berada pada usia produktif yaitu 19-44 tahun. Menurut Aprilyanti (2017), masyarakat yang tergolong usia produktif berpotensi untuk dibina dan dikembangkan kinerjanya agar dapat meningkatkan pendapatan. Setelah peserta mengisi pretest dan daftar hadir, selanjutnya dilakukan penyampaian materi mulai dari tata cara pengolahan nugget pisang, pengemasan, hingga pemasarannya (Gambar 1). Kegiatan pemasaran didasari oleh adanya kebutuhan atau keinginan konsumen terhadapa produk tertentu (Juliana dan Koniyo, 2019).

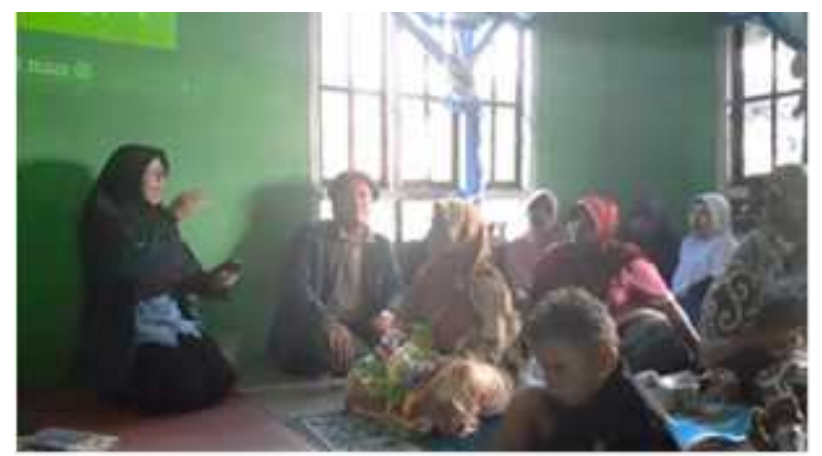

Gambar 1. Penyampaian materi penyuluhan.

Bahan-bahan yang digunakan dalam proses produksi cukup mudah ditemukan, yaitu pisang, keju, gula pasir, telur, susu cair, garam, maizena, vanili, tepung terigu, tepung panir, minyak goreng, dan cokelat yang sudah dilelehkan. Adapun tahapan pembuatannya antara lain yaitu (1) 500 gram pisang dihaluskan dengan garpu; (2) 2 butir telur, 4 sendok makan ( $\mathrm{sdm}$ ) gula pasir, $2 \mathrm{sdm}$ maizena, $1 / 2$ sendok teh (sdt) garam, $1 / 2$ sdt vanili, dan $150 \mathrm{ml}$ susu cair dimasukkan ke dalam adonan pisang yang sudah dihaluskan, kemudian diaduk hingga rata; (3) adonan dimasukkan ke dalam loyang dan dikukus selama 30-45 menit dengan api sedang, kemudian dinginkan dan dipotongpotong hingga berbentuk dadu; (4) bahan pelapis disiapkan dengan cara melarutkan tepung terigu ke dalam air secukupnya; (5) tiap potongan nugget dicelupkan ke dalam larutan tepung terigu lalu gulingkan ke dalam tepung panir hingga terbalut sempurna; (6) nugget dimasukkan ke dalam freezer selama 15-20 menit; (7) nugget digoreng di dalam minyak yang sudah dipanaskan hingga bewarna kecoklatan; dan terakhir (8) nugget ditiriskan kemudian disajikan dengan lelehan cokelat dan taburan keju diatasnya.

Masyarakat sasaran tampak antusis mengikuti kegiatan ini yang nampak pada pertanyaan-pertanyaan yang diajukan saat penyampaian materi dan saat diskusi. Penyampaian materi yang diberikan oleh pemateri kepada peserta penyuluhan menghasilkan tingkat pemahaman yang berbeda-beda, ini dievaluasi menggunakan posttest di akhir kegiatan. Pertanyaan yang terdapat pada posttest merupakan pertanyaan yang sama pada saat pretest. Kemudian, nilai hasil pretest dan posttest 
dibandingkan untuk mengukur tingkat pemahaman peserta penyuluhan terhadap materi yang disampaikan (Gambar 2).

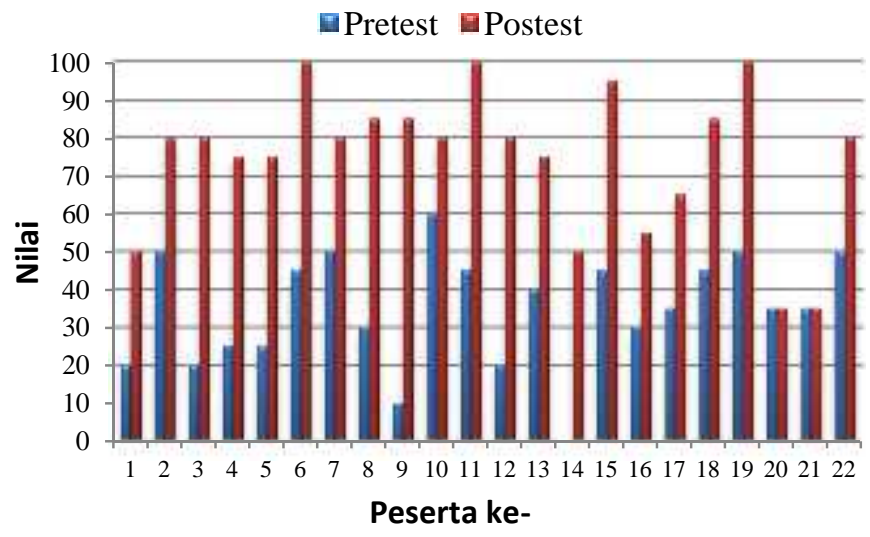

Gambar 2. Hasil pretest dan posttest nugget pisang.

Hasil pretest menunjukkan bahwa masyarakat Desa Banding banyak yang belum mengetahui bahwa pisang dapat diolah menjadi nugget. Pemahaman peserta mengalami peningkatan secara signifikan setelah dilakukannya penyuluhan yang dibuktikan dengan hasil postest. Nilai tertinggi yang dihasilkan saat pretest hanya 60 , sedangkan setelah dilakukannya posttest nilai tertinggi mencapai 100 . Hal ini menunjukkan bahwa kegiatan penyuluhan yang dilakukan berhasil dan materi yang disampaikan mudah diserap oleh peserta.

\section{Tepung Pisang}

Tepung pisang merupakan salah satu alternatif pengganti tepung terigu yang biasa digunakan untuk membuat aneka kue. Sama halnya dengan nugget pisang, produk ini juga belum banyak dikembangkan oleh masyarakat. Pemanfaatan tepung pisang berpotensi untuk dijadikan alternatif pangan fungsional karena memiliki asupan serat yang tinggi (Yasinta et al., 2017). Selain itu, pengembangan usaha ini juga dapat menciptakan kemandirian ekonomi lokal melalui sistem pemberdayaan masyarakat (Syadzali, 2020). Pengembangan ide kreatif pada produk unggulan desa dapat menjadi kunci keberhasilan desa untuk menyejahterakan masyarakatnya (Fauziah et al., 2020).

Kegiatan penyuluhan tepung pisang diawali dengan mengisi daftar hadir dan pretest. Kegiatan ini dihadiri oleh 33 orang peserta yang tergabung dalam Kelompok Tani Hutan (KTH) Desa Sukaraja. Usia peserta yang hadir masih sangat produktif yang berkisar antara 23-55 tahun, sehingga masih memiliki semangat yang tinggi untuk berkreasi dalam berwirausaha. Hal ini sejalan dengan penelitian Rulianto et al. (2018) yang menyatakan bahwa produktifnya usia seseorang cenderung memiliki motivasi kerja yang tinggi dan kemampuan berpikir yang lebih baik.

Pelaksanaan kegiatan penyuluhan di Desa Sukaraja berjalan lancar. Setelah peserta mengisi pretest, kegiatan selanjutnya diisi oleh pemateri yang menyampaikan tentang prosedur pembuatan tepung pisang, cara pengemasan, dan prospek 
penjualannya. Teknik pembuatan tepung pisang cukup mudah dan bahan-bahan yang digunakan juga tidak menguras kantong, sehingga akan menghasilkan keuntungan yang besar (Gambar 3).
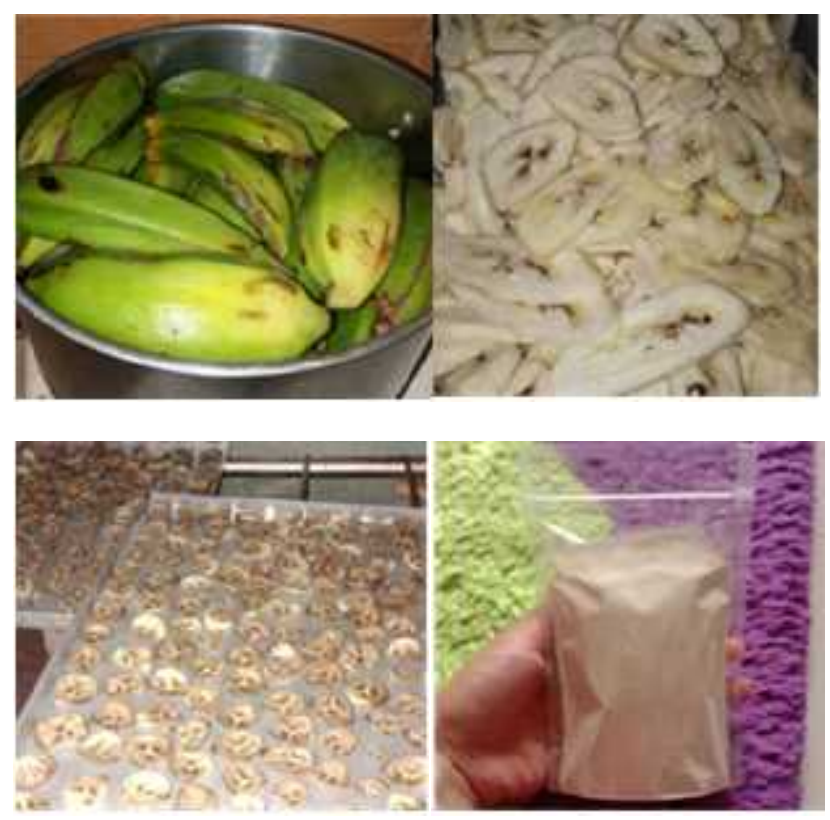

Gambar 3. Proses produksi tepung pisang

Bahan-bahan yang digunakan dalam pembuatan tepung pisang meliputi pisang kepok yang sudah matang, air secukupnya, dan larutan bisulfit. Prosedur pembuatannya yaitu: (1) pisang dikukus selama 15-30 menit, kemudian ditiriskan; (2) kulit pisang dikupas dan dipotong dengan ukuran kurang lebih $0,5 \mathrm{~cm}$; (3) pisang direndam ke dalam larutan bisulfit selama 5 menit untuk mencegah timbulnya warna cokelat pada irisan buah pisang, kemudian ditiriskan kembali; (4) pisang dikeringkan dengan cara dijemur selama 2-3 hari di bawah terik matahari atau menggunakan mesin pengering dengan suhu 80-90oC; dan (5) irisan pisang dihaluskan dengan cara ditumbuk menggunakan alat penumbuk hingga menjadi tepung.

Peserta yang hadir sangat tertarik dengan materi yang disampaikan. Saat dibuka sesi diskusi dan tanya jawab, peserta sangat antusias. Hal tersebut terlihat ketika peserta melontarkan berbagai macam pertanyaan dan ingin menggali lebih dalam lagi tentang produk olahan ini. Menurut Simamora (2019), semakin tinggi minat seseorang terhadap suatu hal, maka akan semakin tinggi pula tingkat rasa ingin tahunya. Beberapa peserta ingin mengembangkan produk ini ke arah yang serius untuk memperkenalkan keunggulan potensi lokal dan meningkatkan perekonomian keluarga. Kegiatan pelatihan dan pembinaan merupakan salah satu cara untuk meningkatkan jiwa kewirausahaan serta dapat meningkatkan kesejahteraan melalui pemberdayaan ekonomi masyarakat luas (Tiarawati dan Widyastuti, 2017).

Setelah mendengarkan penjelasan yang disampaikan oleh pemateri, selanjutnya peserta kembali diberikan bahan pertanyaan untuk mengukur tingkat pemahamannya. Masing-masing peserta mengisi soal posttest yang akan dijadikan parameter dalam 
keberhasilan penyuluhan ini. Kendala yang dihadapi pada saat peserta mengisi soal pretest maupun posttest yaitu ada beberapa peserta yang kesulitan membaca, sehingga untuk mengisi jawabannya, peserta tersebut harus didamping oleh tim penyuluh. Hasil perbandingan pretest dan posttest menunjukkan bahwa terjadi peningkatan pengetahuan masyarakat khususnya tentang pembuatan tepung pisang (Gambar 4).

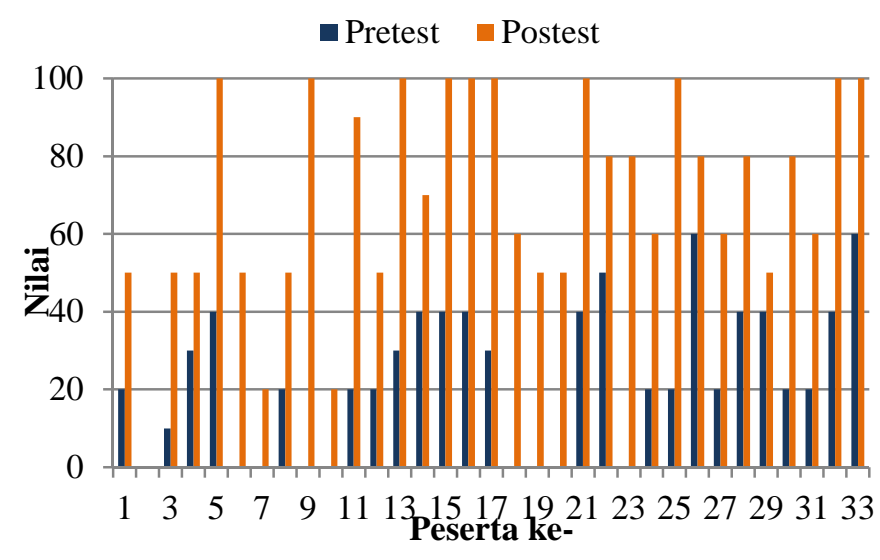

Gambar 4. Hasil pretest dan posttest tepung pisang.

Peningkatan hasil dari pretest ke posttest menunjukkan bahwa peserta dapat memahami materi yang disampaikan dengan baik. Menurut Ardiyanti (2019), salah satu faktor yang mempengaruhi tingkat pemahaman peserta penyuluhan adalah cara penyampaian dan penyajian topik materi yang menarik. Adanya kegiatan ini diharapkan dapat membuat masyarakat menjadi tahu, mau, dan mampu mengembangkan potensi yang ada di daerahnya sehingga dapat meningkatkan perekonomian keluarga.

\section{SIMPULAN}

Kegiatan penyuluhan tentang produk olahan pisang berupa nugget dan tepung mampu meningkatkan pengetahuan masyarakat dan mendorong keinginannya untuk berkreasi dalam mengedepankan produk lokal. Meningkatnya pengetahuan masyarakat dapat dilihat dari hasil posttest yang naik secara signifikan jika dibandingkan dengan pretest. Masyarakat sangat antusias dengan adanya kegiatan ini dan menyadari bahwa masih banyak potensi lokal yang belum dimanfaatkan secara optimal.

\section{DAFTAR RUJUKAN}

Aprilyanti, S. 2017. Pengaruh Usia dan Masa Kerja Terhadap Produktivitas Kerja (Studi Kasus: PT. OASIS Water International Cabang Palembang). Jurnal Sistem dan Manajemen Industri 1(2): 68-72. DOI: 10.30656/jsmi.v1i2.413

Ardiyanti, D. 2019. Penyuluhan dalam Rangka Meminimalisir Penyebaran Hoaks di Kalangan Pelajar. Jurnal Pengabdian Kepada Masyarakat 1(1): 52-55.

Fauziah, Fazriyan, W., Pratama, F. A., and Pratama, S. P. 2020. Pemberdayaan Masyarakat Berbasis Teknologi Informasi untuk Mempromosikan Produk-Produk Unggulan Desa. Jurnal Pengabdian Masyarakat 03(01): 67-73. 
Fikriman, Ulfa, Z., and Susilawati, W. 2020. Analisis Nilai Tambah dan Saluran Pemasaran pada Agroindustri Keripik Pisang di Dusun Purwobakti Kecamatan Bathin III Kabupaten Bungo. Jurnal Agribisnis 2(1): 30-44.

Irundu, D., and Fatmawaty, D. 2019. Potensi Hutan Rakyat Sebagai Penghasil Pangan di Desa Paku Kabupaten Polman, Sulawesi Barat. Jurnal Hutan dan Masyarakat 11(1): 41-48.

Juliana, and Koniyo, Y. 2019. Peningkatan Ekonomi Masyarakat Melalui Pemberdayaan Perempuan Pesisir di Desa Olele Kabupaten Bone Bolango. Jurnal Pengabdian Kepada Masyarakat 3(2): 111-120. DOI: 10.1017/CB09781107415324.004

Mangunsong, L., Zawitri, S., and Susana. 2016. Penganekaragaman Produk Olahan Pisang Didesa Peniti Luar Kabupaten Mempawah Kalimantan Barat. Jurnal Teknologi Pangan 7(2): 62-67. DOI: 10.35891/tp.v7i2.506

Raharjo, T. J., Suminar, T., and Mu'arifuddin. 2016. Peran Pusat Kegiatan Belajar Masyarakat Dalam Menanggulangi Kemiskinan Melalui Pendidikan Nonformal Di Jawa Tengah. Journal of Nonformal Education 2(1): 21-38. DOI: 10.15294/jne.v2i1.5310

Rulianto, S., Malik, A., and Alam, A. S. 2018. Motivasi Masyarakat Desa Mire Terhadap Perlidungan Hutan di Kawasan Hutan Lindung Kecamatan Ulubongka Kabupaten Tojo Una-Una. Jurnal Wanaraksa 6(2): 30-39. DOI: 10.3975/cagsb.2017.02.15

Simamora, R. H. 2019. Pengaruh Penyuluhan Identifikasi Pasien dengan Menggunakan Media Audiovisual Terhadap Pengetahuan Passien Rawat Inap. Jurnal Keperawatan Silampari 3(1): 342-351.

Statistik, B. P. 2015. Lampung Dalam Angka, 2015. Bandar Lampung: BPS Provinsi Lampung.

Syadzali, M. M. 2020. Model Pemberdayaan Masyarakat Melalui Pengembangan Ekonomi Lokal (Studi pada UKM Pembuat Kopi Muria). Syntax Idea 2(5): 91-97. DOI: $10.1017 /$ CBO9781107415324.004

Tambajong, H. Di, Sondakh, M. F. L., and Tarore, M. L. G. 2020. Analisis Keuntungan Usaha Gorengan "Ibu Nouke" di Kelurahan Bahu Kecamatan Malalayang Kota Manado. Jurnal Transdisiplin Pertanian (Budidaya Tanaman, Perkebunan, Kehutanan, Peternakan, Perikanan), Sosial dan Ekonomi 16(1): 97-104.

Tiarawati, M., and Widyastuti. 2017. Pemberdayaan Remaja Panti Asuhan Melalui Pembuatan Nugget Guna Menumbuhkan Minat Berwirausaha. Jurnal Pengabdian Kepada Masyarakat 1(1): 118-127. DOI: 10.1017/CB09781107415324.004

Yasinta, U. N. A., Dwiloka, B., and Nurwantoro. 2017. Pengaruh Subtitusi Tepung Terigu Dengan Tepung Pisang Terhadap Sifat Fisikokimia Dan Organoleptik Cookies. Jurnal Aplikasi Teknologi Pangan 6(3): 119-123. DOI: 10.17728/jatp.200 